Website: http://revistas.lamolina.edu.pe/index.php/acu/index

(C) Universidad Nacional Agraria La Molina, Lima - Perú

\title{
Uso de inductores de defensa en el control de infecciones ocasionadas por Lasiodiplodia theobromae, en plantones de vid (Vitis vinifera) en Perú
}

\author{
Use of defense inductors in the control of infections caused by Lasiodiplodia theobromae, in vine \\ plant (Vitis vinifera) in Peru
}

\section{Jose Miguel Soto Heredia ${ }^{1 *} \&$ Carlos Alberto Cadenas Giraldo ${ }^{2}$}

*Autor de correspondencia

\begin{abstract}
Resumen
El objetivo del presente trabajo de investigación fue evaluar el efecto de seis sustancias químicas (Ácido fosforoso, fosetil aluminio, fosfito de potasio, sulfato de cobre pentahidratado, mananos oligosacáridos, acibenzolar-S-metil) y dos agentes biológicos (Bacillus subtilis y Trichoderma harzianum), en el control de Lasiodiplodia theobromae, utilizados como inductores de defensas en plantones de vid 'Red Globe” injertados sobre patrón 'Harmony'. Los cuales primero fueron inoculados con micelio de L. theobromae mediante una herida, tanto en la variedad como en el patrón. A los cinco días después de la inoculación se realizaron tres aplicaciones consecutivas de los tratamientos con intervalos de diez días entre ellas. Las evaluaciones se hicieron a los 40 días después de la inoculación y se consideró tanto la incidencia como la severidad de las lesiones necróticas presentes. Para la de incidencia se calculó el número de plantas con lesiones y para la severidad se utilizó el programa de análisis de imagen ASSESS 9.1 para determinar el área de la lesión $\left(\mathrm{cm}^{2}\right)$. Para el análisis estadístico se utilizó un diseño completamente al azar (DCA), una comparación de medias Tukey con un nivel se significancia del $95 \%(\alpha=0,05)$. Los mejores resultados se obtuvieron con los tratamientos con los menores porcentajes de incidencia: mananos oligosacáridos $0 \%$ en el injerto y 33,3\% en el patrón y acibenzolar-S-metil con 8,3 \% en el injerto y 58,3 \% en el patrón, los cuales mostraron eficaces en el control de la enfermedad ocasionada por L. theobromae.
\end{abstract}

Palabras clave: Acibenzolar-S-metil; Red Globe; mananos oligosacáridos; inductores de resistencia.

\begin{abstract}
The objective of this research work was to evaluate the effect of six chemical substances (Phosphorous acid, aluminum fosetyl, potassium phosphite, copper sulfate pentahydrate, mannans oligosaccharides, acibenzolar-S-methyl) and two biological agents (Bacillus subtilis and Trichoderma harzianum), for the control of Lasiodiplodia theobromae, used as defense inducers in grape plants 'Red Globe' grafted onto 'Harmony' rootstock which initially were inoculated using $L$. theobromae mycelium placed in a wound on both the scion and the rootstock. Five after days after the inoculation three applications of the treatments were done with intervals of ten days between one application and the next application. Evaluations were done 40 days after the inoculation recording disease incidence and severity. Disease incidence was calculated with the number of plants showing necrotic lesions and severity was estimated using ASSESS 9.1 image analysis program to determine lesion area $\left(\mathrm{cm}^{2}\right)$. For the statistical analysis we used a completely randomized design (DCA), a comparison of Tukey means with a level of significance of $95 \%(\alpha=0,05)$. The best results were obtained with the treatments with lower percentages of incidence: mannans oligosaccharides $0 \%$ in the graft and 33,3\% in the patterns and acibenzolar-S-methyl with $8,3 \%$ in the graft and 58,3\% in the patterns, which showed effective in the control of the disease caused by L. theobromae.
\end{abstract}

Key words: Acibenzolar-S-methyl; Red Globe; mannans oligosaccharides; resistance inductors.

\section{Introducción}

El cultivo de la vid (Vitis vinifera L.) es uno de los más extensamente cultivados en el mundo, cubre un área de 10 millones de hectáreas aproximadamente Se desarrolla tanto en regiones templadas como tropicales, pero la mayoría de los viñedos están establecidos en zonas de climas templados, concentrándose la mayor cantidad en Europa. Constituye también una de las actividades frutícolas de mayor importancia en el Perú por su extensión, valor de producción y por ser fuente de la materia prima que requiere la industria vitivinícola nacional (Pearson, 2011). En la actualidad, hay cerca de 29,777 hectáreas cultivadas con uvas de mesa para la exportación en la costa peruana, desde Moquegua hasta Piura. Ica es la principal región productora con el 40,7 \% del volumen nacional exportado, seguido por Piura con el 23,7 \% y Lima con 13,3 \% (MINAGRI, 2017).

\footnotetext{
${ }^{1}$ Departamento Académico de Fitopatología, Facultad de Agronomía, Universidad Nacional Agraria La molina, Apartado postal 12-056- La Molina, Lima, Perú. Email: Jomish28@hotmail.com

${ }^{2}$ Departamento Académico de Fitopatología, Facultad de Agronomía, Universidad Nacional Agraria La molina, Apartado postal 12-056- La Molina,

Lima, Perú. Email: ccadenas@lamolina.edu
} 
La vid es afectada por diversas enfermedades que merman la producción tales como la muerte regresiva (Lasiodiplodia theobromae), la enfermedad de Petri (Phaeoacremonium spp. y Phaeomoniella chlamydospora), la Eutipiosis (Eutypa lata), la Yesca (Fomotiporia mediterranea), etc. (Reynier, 1989).

L. theobromae (Pat.) Griffon and Maubl. es la especie tipo del género Lasiodiplodia, el cual es un hongo que fue descrito por primera vez hacia 1890 por Saccardo, afectando frutos de cacao (Theobromae cacao) en Ecuador (Crous \& Palm, 1999). Este hongo es cosmopolita y tiene una amplia gama de hospederos, incluidos monocotiledóneas, dicotiledóneas y gimnospermas, especialmente de los trópicos y subtrópicos. Es un hongo pleomórfico y ubicuo, por lo cual ha tenido más de un sinónimo (Abdollahzadeh et al., 2010; Wang et al., 2011).

La muerte regresiva de la vid, causada por $L$. theobromae, ocasiona una reducción del crecimiento y un decaimiento general de las plantas. Esta enfermedad afecta principalmente a las plantas jóvenes causando enormes pérdidas en nuevas plantaciones. (Mugnai et al., 1999; Poscoe y Cotral, 2000).

En campos instalados con vid es difícil curar las plantas infectadas con L. theobromae debido a que este hongo se localiza en los tallos, tanto a nivel de patrón como en el injerto, siendo la principal fuente de inóculo el material de propagación infectado, por tal motivo, durante el proceso de propagación de la vid en vivero y en campo, se debe tomar medidas que eviten la contaminación del material (Mugnai et al., 1999; Poscoe y Cotral, 2000).

Existen antecedentes del potencial de ciertos productos químicos para el control de diversas enfermedades como el caso de Tomato spotted wilt virus (Mandal, et al., 2008), Pseudomonas lachrymans y Colletotrichum lagenarium haciendo aplicaciones exógenas en la zona foliar (Kuc \& Richmond, 1977), y biológicos en el control de Botrytis cinerea, Armillaria spp., Colletotrichum gloesporioides, Cylindrocladium scoparium, Fusarium moniliforme, Fusarium oxysporum, Pythium spp. y Sclerotinia sclerotiorum (Añon et al., 2004). Por ello, en esta investigación se tuvo como objetivo general determinar la eficacia en vivero de seis productos inductores de defensa de naturaleza química: Ácido fosforoso, fosetil aluminio, fosfito de potasio, sulfato de cobre pentahidratado, mananos oligosacáridos y acibenzolar S-metil así como dos de naturaleza biológica: Bacillus subtilis y Trichoderma harzianum; utilizados como para el control de la muerte regresiva causada por $L$. theobromae en plantones de vid en vivero.

\section{Materiales y métodos}

El presente trabajo de investigación se realizó en el vivero de la empresa Los Viñedos ubicado en el Kilómetro 201 de la Panamericana Sur, perteneciente al fundo El Retiro Lote 75, Distrito de Chincha Baja, Provincia de Chincha, Departamento de Ica.

Para la obtención del inóculo que se utilizó en este estudio, 354 en campo se seleccionaron plantas madre de vid de la variedad Red Globe con síntomas de muerte regresiva, característicos de las infecciones con L. theobromae. Los brotes de las plantas seleccionadas se cortaron con una tijera de podar y fueron colocados en una bolsa de polipropileno y llevados al laboratorio para realizar el aislamiento del patógeno. Las ramas o brotes con su zona de avance asintomático fueron seleccionadas y se lavaron con agua potable, se cortaron en porciones pequeñas de aproximadamente $5 \mathrm{~mm}$ de diámetro abarcando la zona de avance de la enfermedad, enseguida se procedió a colocarlas en una solución de alcohol al $96 \%$ por 5 minutos con el propósito de eliminar los contaminantes y microorganismos superficiales y luego se dejaron secar sobre papel toalla estéril, siguiendo los procedimientos realizado por Abdollahzadeh et al. (2010).

Las porciones de tejido, desinfestadas y secas, se sembraron en placas Petri conteniendo medio de cultivo Extracto de Malta Agar (MEA) marca Merck disponiendo 5 porciones en forma de cruz. Las placas sembradas se colocaron por cuatro días en la incubadora a una temperatura de $25{ }^{\circ} \mathrm{C}$ para permitir el crecimiento del hongo (Santiago et al., 2015). Transcurrido el tiempo se hicieron observaciones al microscopio estereoscópico para determinar la presencia de las esporulaciones del hongo. Se hicieron preparaciones microscópicas de las estructuras fructificantes formadas en las colonias en láminas porta y cubreobjetos las cuales fueron observadas al microscopio compuesto para la identificación correspondiente. Se utilizó la clave de Barnett y Hunter (1996) para corroborar el género taxonómico; y la clave de Sutton (1980) y el descriptor de la Commonwealth Mycological Institute CMI 1974 para la corroboración a nivel de especie.

El hongo ya identificado se inoculó en plantones de vid para determinar la patogenicidad de $L$. theobromae extraídas de plantas sintomáticas, en la cual se utilizó el mismo material vegetal y metodología empleados en los tratamientos.

Para la fase de vivero se utilizaron estacas enraizadas de vid sanos de la variedad Red Globe injertadas sobre patrón Harmony que previamente fueron pasadas por un proceso de termoterapia a temperatura de $53{ }^{\circ} \mathrm{C}$ por 30 minutos. Se plantaron en diez bandejas con sustrato estéril compuesto por una mezcla de coco, humus y pajilla de arroz en las proporciones (1-1-1/2) siendo 12 plantones en cada una, dando un total de 120 plantones.

Para la inoculación del hongo en cada plantón de vid se hicieron dos heridas circulares de $5 \mathrm{~mm}$ de diámetro en el tallo, una en la zona del patrón y la otra en la zona de la variedad injertada, utilizando un sacabocado previamente desinfectado, ejerciendo una presión leve en el tallo para extraer la porción de corteza. En el área de tejido expuesta se colocó una rodaja de $5 \mathrm{~mm}$ de medio MEA conteniendo el crecimiento de 4 días de edad de micelio de L. theobromae. Las heridas inoculadas se cubrieron con un trozo pequeño de algodón humedecido con agua destilada estéril para generar humedad al hongo y finalmente se envolvió con cinta parafilm, esta metodología fue adaptada a o realizado 
por Urbez-Torres et al. (2009). Los plantones inoculados se dejaron crecer dentro de un tinglado de malla Raschel hasta la observación de los síntomas secundarios y primarios; así como de la presencia de los signos correspondientes.

Los productos que se evaluaron en el presente trabajo de investigación fueron ocho en total, seis de naturaleza química y dos de naturaleza biológica, los cuales se presentan en la Tabla 1.

Tabla 1. Tratamientos de productos químicos y biológicos contra $L$. theobromae, en fase de vivero

\begin{tabular}{cccc}
\hline Tratamiento & Ingrediente activo & Dosis & Aplicación \\
\hline 1 & Acido fosforoso & $1,0 \mathrm{~L} / 200$ & Drench \\
2 & Fosetil de Aluminio & $0,5 \mathrm{~kg} / 200 \mathrm{~L}$ & Foliar \\
3 & Fosfito de potasio & $0,5 \mathrm{~L} / 200 \mathrm{~L}$ & Foliar \\
4 & Sulfato de cobre & $0,4 \mathrm{~L} / 200 \mathrm{~L}$ & Foliar \\
5 & pentahidratado & & \\
6 & Mananos oligosacáridos & $0,5 \mathrm{~L} / 200 \mathrm{~L}$ & Foliar \\
7 & Acibenzolar S-methyl & $10,0 \mathrm{~g} / 200 \mathrm{~L}$ & Foliar \\
8 & Trichoderma harzianum & $5 \mathrm{~g} / \mathrm{L}$ & Foliar \\
9 & Bacillus subtilis $(0,2 \%)$ & $5 \mathrm{~g} / \mathrm{L}$ & Foliar \\
10 & Testigo sin inocular & Agua sola & Foliar \\
\hline
\end{tabular}

Se realizó la aplicación de los productos en la zona foliar y vaciado al suelo para un solo tratamiento, ya que aplicaciones en estas zonas en investigaciones anteriores muestran que estos productos pueden ejercen un efecto de control en diversos cultivos (Matos et al., 2013). Para el primer caso se utilizó un asperjador manual de la marca "Arsus" con capacidad de 2 litros, los ingredientes activos fueron pesados en la cantidad equivalente a la dosis comercial y mezclados con agua en una cantidad de $360 \mathrm{ml}$ por tratamiento con adición de un surfactante siliconado para disminuir la tensión superficial del agua permitiendo un mojamiento uniforme, para la aplicación en suelo se realizó un vaciado al sustrato en una cantidad de $400 \mathrm{ml}$ de agua. Para permitir el establecimiento del patógeno inoculado se esperó cinco días para la aplicación de los tratamientos, pues de acuerdo con Al-Saadoon et al. (2012) después de la inoculación se vio una degeneración de la epidermis y células parenquimaticas de la corteza en plantas de vid inoculadas con $L$. theobromae, siendo estas llevadas a cabo en tres oportunidades en intervalos de diez días entre una aplicación y otra.

Transcurridos 40 días después de la inoculación, se realizaron las evaluaciones de los plantones en todos los tratamientos considerando el tiempo necesario para que se produzca las infecciones y activación de respuesta de la planta en caso existiera. Los parámetros que se registraron fueron: a. Incidencia, contando el número de plantas que mostraron síntoma visual de pudrición externa en avance en los tallos que fue ocasionado directamente por el patógeno inoculado; b. Severidad externa, para lo cual se efectuó un raspado de la superficie de los tallos desde los puntos de inoculación hacia sus cuatros lados (superior, inferior, izquierda y derecha) exponiendo el tejido cortical afectado; evaluándose tanto de la zona del patrón como en la del injerto. Se calcó el área afectada colocándola papel celofán ceñido al tallo, posteriormente estos dibujos fueron copiados a un papel blanco y para determinar el área afectada estos fueron llevados al gabinete donde se utilizó el programa de análisis de imagen para la cuantificación de la enfermedad en plantas (ASSESS 9.1); c. Severidad interna, después del raspado superficial de los tallos, se realizaron cortes longitudinales para medir el avance de la necrosis por los haces vasculares, tanto hacia arriba como hacia abajo del punto de inoculación, y para esta evaluación se utilizó una regla calibrada en milímetros (mm). d. Porcentaje de inhibición del hongo, la cual se utilizó la formula \% Inhibición $=\{[$ (Testigo inoculado Tratamiento) / Testigo inoculado) $\mathrm{x} 100\}$.

El diseño experimental que se empleó fue Completamente al Azar (DCA), con 10 tratamientos en total y 12 repeticiones por cada uno. Para las variables evaluadas se realizaron Análisis de homogeneidad de variancia y normalidad y la Prueba de comparación de medias de Tukey, considerando un nivel de confianza del $95 \%(\alpha=0,05)$, para lo cual se utilizó el Statistical Analisys Software (SAS Institute, 2004), versión 9.0.

\section{Resultados y discusión}

En la prueba de patogenicidad (Postulado de koch) se observó los mismos síntomas vistos en las plantaciones madre de donde se obtuvo los aislados las cuales fueron plantones con pérdidas de vigor, reducción de los entrenudos, hojas son síntomas cloróticos y la presencia de signo las cuales son las picnidias con la presencia de cirrus (Úrbez-Torres et al., 2008).

Los resultados de las evaluaciones de incidencia de la enfermedad (Tabla 2), se detectó que los tratamientos a base de: fosfito de potasio, sulfato de cobre pentahidratado, ácido fosforoso, B. subtilis, fosetil de aluminio y T. harzianum además del testigo inoculado, presentaron un $100 \%$ de incidencia de la enfermedad tanto en el patrón como en el injerto. En el tratamiento con mananos oligosacáridos se observaron cuatro plantas con infecciones solamente en el patrón mas no en injerto; y en el tratamiento con acibenzolar-S-metil se tuvo una planta con infección tanto en la zona del patrón como en el injerto y siete plantas infectadas solamente en la zona del patrón.

Como las aplicaciones de los productos fueron a la zona foliar, por lo tanto, las primeras reacciones de defensa se esperaría que se presentaran en las hojas, luego en la zona cerca al injerto y posteriormente las defensas se movilizarán en forma sistémica hacia el patrón. Esto explicaría el por qué algunos tratamientos mostraron tener infecciones en la zona del patrón a pesar que sus injertos no lo tenían, posiblemente se deba a que existe una zona de injertación donde el paso del señalizador MeSa para la activación de la resistencia en toda la planta es obstruida y/o retardada lo cual permite el avance de la infección antes de que se produzca la reacción de defensa, pudiendo darse resultados como los obtenidos en estos tratamientos y sustentados en otros trabajos como los de Shulaev et al., 1995. 
Tabla 2. Incidencia de infección por L. theobromae en plantas de vid inoculadas en el patrón e injerto

\begin{tabular}{|c|c|c|c|c|}
\hline $\mathrm{N}^{\circ}$ & Tratamiento & $\begin{array}{c}\text { Zona de la } \\
\text { planta }\end{array}$ & $\begin{array}{c}\mathrm{N}^{\circ} \mathrm{de} \\
\text { plantas } \\
\text { afectadas }\end{array}$ & Incidencia \% \\
\hline \multirow{2}{*}{10} & \multirow{2}{*}{ Testigo inoculado } & Injerto & $12 / 12$ & 100 \\
\hline & & Patrón & $12 / 12$ & 100 \\
\hline \multirow{2}{*}{3} & \multirow{2}{*}{ Fosfito de potasio } & Injerto & $12 / 12$ & 100 \\
\hline & & Patrón & $12 / 12$ & 100 \\
\hline \multirow{2}{*}{8} & \multirow{2}{*}{ Bacillus subtilis } & Injerto & $12 / 12$ & 100 \\
\hline & & Patrón & $12 / 12$ & 100 \\
\hline \multirow{2}{*}{1} & \multirow{2}{*}{ Ac. fosforoso } & Injerto & $12 / 12$ & 100 \\
\hline & & Patrón & $12 / 12$ & 100 \\
\hline \multirow{2}{*}{7} & \multirow{2}{*}{ T. harzianum } & Injerto & $12 / 12$ & 100 \\
\hline & & Patrón & $12 / 12$ & 100 \\
\hline \multirow{2}{*}{4} & \multirow{2}{*}{ Sulfato de cobre Pent. } & Injerto & $12 / 12$ & 100 \\
\hline & & Patrón & $12 / 12$ & 100 \\
\hline \multirow{2}{*}{2} & \multirow{2}{*}{ Fosetil aluminio } & Injerto & $12 / 12$ & 100 \\
\hline & & Patrón & $12 / 12$ & 100 \\
\hline \multirow{2}{*}{5} & \multirow{2}{*}{ Mananos oligosacáridos } & Injerto & $0 / 12$ & 0 \\
\hline & & Patrón & $4 / 12$ & 33,3 \\
\hline \multirow{2}{*}{6} & \multirow{2}{*}{ Acibenzolar-S-Methil } & Injerto & $1 / 12$ & 8,3 \\
\hline & & Patrón & $7 / 12$ & 58,3 \\
\hline \multirow{2}{*}{9} & \multirow{2}{*}{ Testigo sin inocular } & Injerto & $0 / 12$ & 0 \\
\hline & & Patrón & $0 / 12$ & 0 \\
\hline
\end{tabular}

Las comparaciones de las áreas de las infecciones por $L$. theobromae entre patrón e injerto en los diversos tratamientos se presenta en la Figura 1, donde se observa que hubo diferencias en las áreas con avance de la infección entre el injerto y el patrón. Las áreas afectadas en los injertos fueron menores comparadas con las de los patrones en la mayoría de los tratamientos.

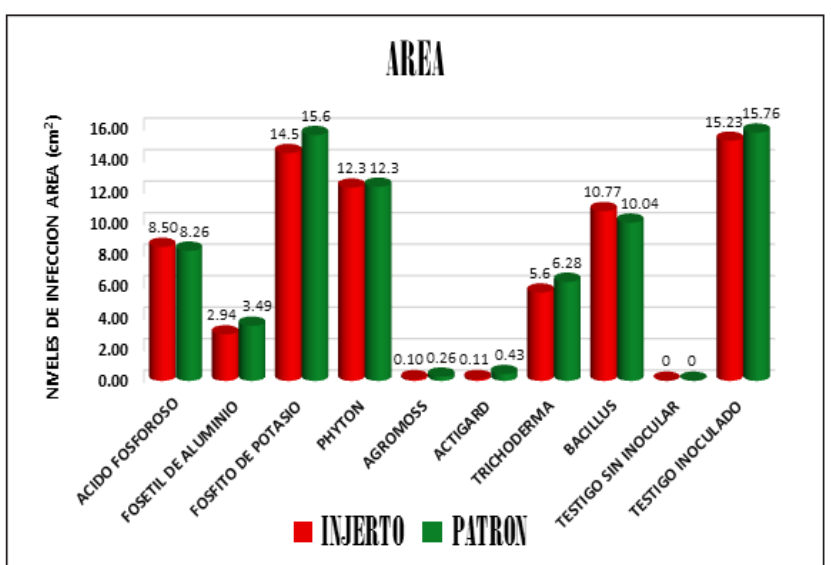

Figura 1. Comparaciones de áreas de las infecciones por $L$ theobromae entre los injertos y patrones en plantas de vid tratadas con productos químicos y biológicos

Los síntomas de pudrición que se presentaron en los diversos tratamientos evaluados para el caso de tallos en la zona de los injertos se pueden observar en la Figura 2 y en los tallos en la zona de los patrones en la Figura 3. Las infecciones en los tallos de los plantones a partir del punto de inoculación tanto en la zona del injerto como en el patrón se pudieron notar que en estos últimos fueron mayores hacia la parte de abajo que las de arriba, resultados similares ffueron obtenidos por Urbez-Torres et al. (2008).

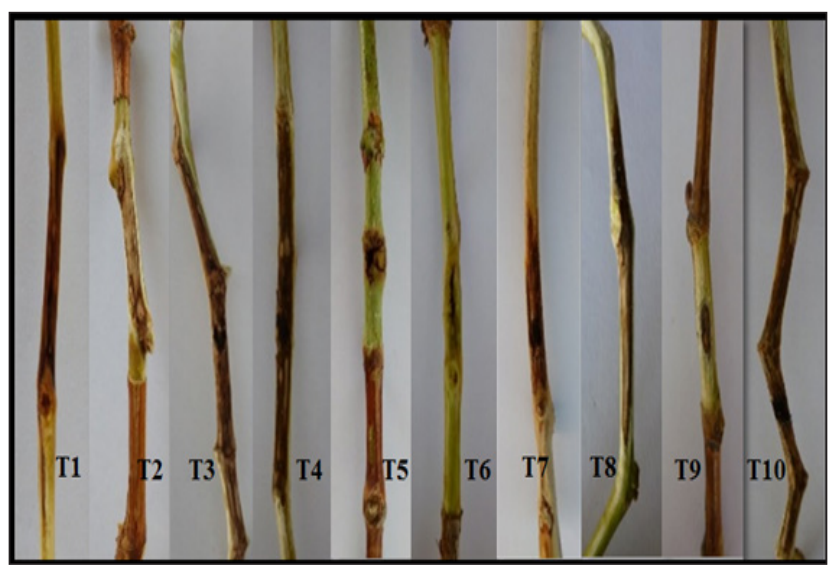

Figura 2. Síntomas de pudrición en la zona del tallo del injerto en plantas de vid en: T1 (Ac. fosforoso), T2 (Fosetil aluminio), T3 (Fosfito de potasio), T4 (Sulfato de cobre pentahidratado), T5 (Mananos oligosacáridos), T6 (Acibenzolar-S-metil), T7 (Trichoderma harzianun), T8 (Bacillus subtilis), T9 (Testigo sin inocular) y T10 (Testigo inoculado)

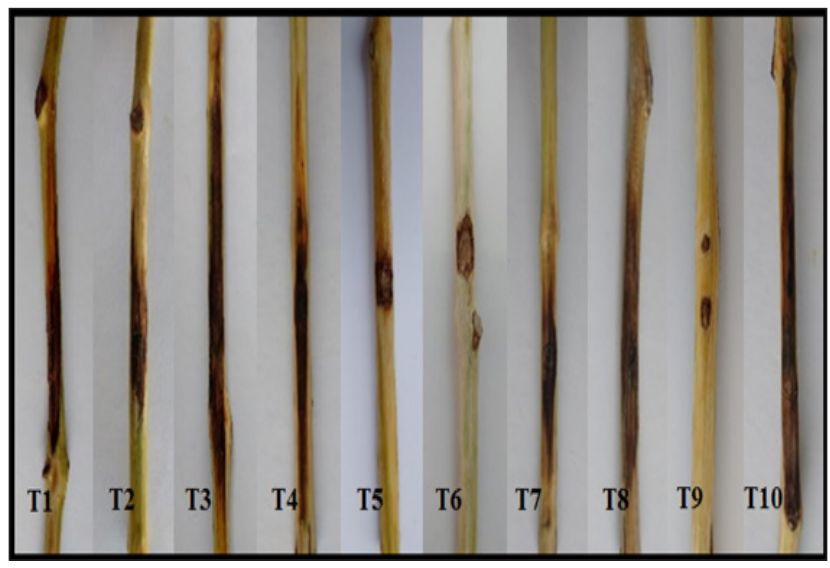

Figura 3. Síntomas de pudrición en la zona del tallo del patrón en plantas de vid en: T1 (Ac. fosforoso), T2 (Fosetil aluminio), T3 (Fosfito de potasio), T4 (Sulfato de cobre pentahidratado), T5 (Mananos oligosacáridos), T6 (Acibenzolar-S-metil), T7 (Trichoderma harzianun), T8 (Bacillus subtilis), T9 (Testigo sin inocular) y T10 (Testigo inoculado)

El avance longitudinal de la infección por $L$. theobromae en el patrón e injerto de las plantas de vid en los diversos tratamientos se presenta en la Figura 4, donde se observa que el avance longitudinal en el injerto. En seis tratamientos La infección fue mayor en comparación con el patrón en la mayoría de los tratamientos.

En los tratamientos que mostraron infección se observaron diferencias en las mediciones de avance longitudinal y lateral de la necrosis en los tejidos de la variedad con respecto al patrón. Se pudo notar que la 
distancia de avance longitudinal a partir del punto de inoculación fue mayor en el injerto, estas diferencias podrían deberse a factores como tipo de tejido inoculado, edad del hospedante y/o diferencias en la susceptibilidad del cultivar, entre otros factores que influyan en el avance del patógeno (Van \& Pieterse et al. 2004).

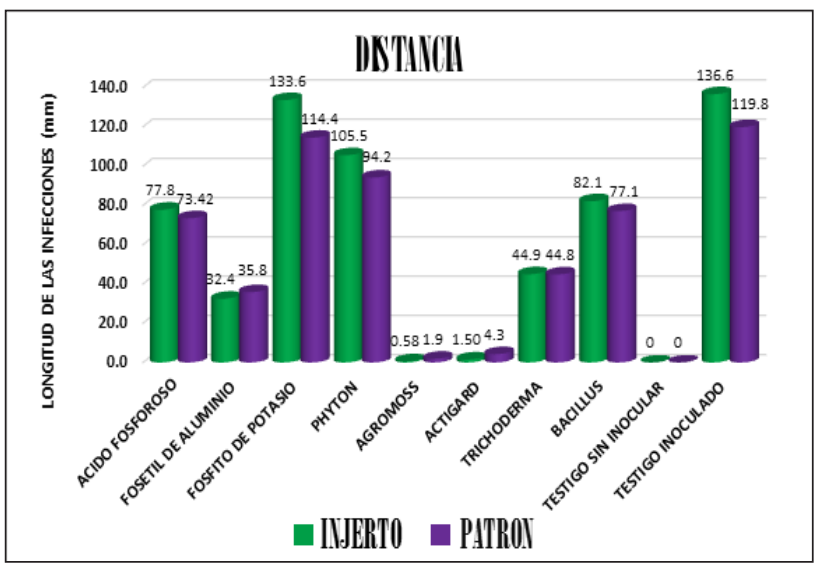

Figura 4. Comparaciones de longitudes de las infecciones por $L$ theobromae entre los injertos y los patrones en plantas de vid tratadas con productos químicos y biológicos

Mientras que el avance lateral fue superior en el patrón. Por otro lado, cuando se evaluaron las áreas de avance de las infecciones ocasionado por $L$. theobromae en los tejidos, las mediciones mostraron que las áreas afectadas de los patrones fueron mayores que en la variedad injertada. De lo anterior se puede considerar que el área de infección podría ser considerado un parámetro de medición más adecuado ya que considera tanto la longitud, así como el ancho en comparación a mediciones de longitud, en donde solo se considera hasta dónde en dirección recta se ve la necrosis.

Los avances longitudinales de las infecciones en los injertos fueron mayores en comparación a los patrones, esto pudo deberse a que los injertos son brotes tiernos de tres meses de edad con rápido crecimiento longitudinal comparados con los patrones que son material vegetal de mayor edad y con mayor lignificación. Rodriguez et al. (2015) comenta que plantas jóvenes no lignificadas infectadas con L. theobromae también presentan un avance rápido de infección.

Los tratamientos con mananos oligosacáridos y con acibenzolar-S-metil mostraron tener eficacia en el control curativo de la infección por $L$. theobromae, las infecciones fueron bloqueadas (Se observa la formación de callo) a pesar de haber trascurrido cinco días después de la inoculación. Estos dos fueron buenos en el control por registrar los menores niveles de incidencia tanto el injerto como el patrón comparados con los demás tratamientos. En estudios similares se detectó el poder activador de defensa en plantas, tratadas con ácido salicílico aplicado exógenamente para Botrytis cinerea (Renault et al., 1996) y aplicaciones de mananos oligosacáridos contra
Plasmopara viticola en vid, donde mostraron tener buena eficacia como activadores de defensa contra patógenos en plantas (Kedma et al., 2012).

Los productos a base de fósforo como el caso de ácido fosforoso y fosfito de potasio no mostraron tener ningún efecto positivo en el control de la infección por L. theobromae, estas alcanzaron niveles casi igual a las del testigo inoculado, existe reportes con estos productos para otros cultivos con diferente patógeno, donde si mostraron tener cierta eficacia en el control. Su poca eficacia en el control puede ser explicado que no hay fundamentos en que estos productos activen la defensa de manera sistémica; pero los mecanismos de defensas no son solamente de forma sistémica, siendo también mediante la producción de compuestos microbicidas como las fitoalexinas, de ser así, no necesariamente pueden producirse fitoalexinas en cantidades elevadas como para inhibir el avance del patógeno. Esto quizá pudiera ser manejado por la dosis del producto a aplicar, ya que en el presente trabajo de investigación las cantidades de los productos que se aplicaron fueron en relación a la dosis comercial recomendada y no necesariamente a una dosis que pueda funcionar como inductor de defensas en cantidades suficientes.

En comparación, el tratamiento con fosetil aluminio que, a pesar de tener cierto efecto positivo en el control, el avance de la infección fue bastante progresivo, por lo cual no existió el bloqueo total de la misma. Hay investigaciones que muestran que la aplicación de Fosetil aluminio participa en la producción de fitoalexinas y otros compuestos fenólicos, aunque también hay otros estudios que demuestran que la acumulación de fitoalexinas en plantas tratadas con Fosetil aluminio fueron iguales que en las plantas no tratadas. Por lo tanto, no se puede asociar a las fitoalexinas las respuestas relacionadas con la defensa en el hospedante (Guest, 1986). Entre los procesos de defensa de la planta se incluyen las muertes programadas de las células, y no solo existe una muerte como tal, sino que se forman y acumulan otros compuestos que son tóxicos para el patógeno y las células hospedantes (Heath, 2000).

Los productos biológicos como el caso de Bacillus subtilis y el hongo Trichoderma harzianun no presentan efecto positivo en el control, considerando que las aplicaciones fueron a nivel foliar y Lasiodiplodia theobromae un patógeno endófito, de existir un control se podría postular a alguna inducción de defensa de estos productos, estudios como los de Ziplel (2014) señalan que para que exista la activación de genes relacionados a la defensa tiene que existir un reconocimientos de los elicitores o en otro nivel de los efectores y esto sucede de manera específica cual explicaría que estos microorganismo no elicitan respuesta alguna por no ser moléculas reconocidas por la planta.

El análisis de varianza de las áreas de las lesiones en los injertos indicó que había diferencias altamente significativas entre los tratamientos. Los resultados de la prueba de comparación de medias de Tukey $(0,05)$ del área 
de avance de la infección en los injertos de las plantas en que se evaluaron los tratamientos se presentan en el Tabla 3 $\mathrm{y}$, nos indican que los mejores resultados se obtuvieron con los tratamientos mananos oligosacáridos y acibenzolarS-metil, cuya severidad de infección representada en área $\left(\mathrm{cm}^{2}\right)$ fue de 0,09 y 0,10 respectivamente, fueron estadísticamente iguales a lo obtenido en el testigo sin inocular. El tratamiento con fosetil aluminio tuvo un promedio de $2,94 \mathrm{~cm}^{2}$, representando un porcentaje de control mayor al $80 \%$, por lo que estos tres tratamientos si mostraron tener un efecto inductor. Los tratamientos con Trichoderma harzianun y ácido fosforoso, tuvieron una severidad media de 5,60 y $8,50 \mathrm{~cm}^{2}$ respectivamente, con porcentajes bajos de control respecto al testigo, lo cual indica que los dos tratamientos tuvieron un efecto poco importante sobre la enfermedad.

Los tratamientos a base de Bacillus subtilis y sulfato de cobre pentahidratado, tuvieron una severidad media de infección de 10,75 y $12,27 \mathrm{~cm}^{2}$, respectivamente, no existiendo diferencias estadísticas entre estos tratamientos.

El tratamiento con fosfito de potasio y el testigo inoculado tuvieron la máxima severidad media de infección de 14,45 y $15,25 \mathrm{~cm}^{2}$, respectivamente, representando un control de la enfermedad menor a $30 \%$ para el mejor caso.

Tabla 3. Resultados del análisis de área de las infecciones por $L$. theobromae en el injerto de plantas de vid con distintos tratamientos para el control de la enfermedad

\begin{tabular}{|c|c|c|c|}
\hline Tratamientos & $\begin{array}{l}\text { Media del } \\
\text { área de } \\
\text { infección } \\
\text { real }\end{array}$ & $\begin{array}{c}\text { Media } \\
\text { transformada } \\
\text { de área de } \\
\text { infección }\end{array}$ & Agrupamiento \\
\hline Testigo inoculado & $15,25^{\mathrm{x}}$ & $4,90^{y}$ & $\mathrm{~A}^{\mathrm{z}}$ \\
\hline Fosfito de potasio & 14,45 & 4,79 & $\mathrm{AB}$ \\
\hline $\begin{array}{l}\text { Sulfato de cobre } \\
\text { pentahidratado }\end{array}$ & 12,27 & 4,49 & B \\
\hline Bacillus subtilis & 10,75 & 4,27 & $\mathrm{~B}$ \\
\hline Ácido fosforoso & 8,50 & 3,91 & $\mathrm{C}$ \\
\hline Trichoderma harzianun & 5,60 & 3,36 & $\mathrm{D}$ \\
\hline Fosetil aluminio & 2,94 & 2,69 & $\mathrm{E}$ \\
\hline Acibenzolar-S-metil & 0,10 & 1,17 & $\mathrm{~F}$ \\
\hline Mananos oligosacáridos & 0,09 & 1,09 & $\mathrm{~F}$ \\
\hline Testigo sin inocular & 0,00 & 1,00 & $\mathrm{~F}$ \\
\hline Coeficiente de variabilidad & $4,47 \%$ & & \\
\hline
\end{tabular}

El análisis de varianza de las áreas de las lesiones en los patrones indicó la existencia de diferencias altamente significativas entre los tratamientos. Los resultados de la prueba de comparación de las medias de Tukey $(0,05)$ de área de avance de la infección en los patrones de las plantas de vid en que se aplicaron los tratamientos se encuentran en la Tabla 4. Los mejores resultados se obtuvieron nuevamente con los tratamientos mananos oligosacáridos, acibenzolar- S- metil, cuya severidad de infección fue de 0,26 y $0,42 \mathrm{~cm}^{2}$, respectivamente. El tratamiento fosetil aluminio tuvo un promedio de $3,37 \mathrm{~cm}^{2}$, representando un porcentaje de control mayor del $75 \%$, por lo que estos tres tratamientos mostraron un buen efecto en la inducción de defensa natural.

Los tratamientos con T. harzianun y ácido fosforoso, tuvieron una severidad media de infección de 6,28 y 8,25 $\mathrm{cm}^{2}$, respectivamente, con porcentajes bajos de control con respecto al testigo, lo cual nos indica que tienen un efecto poco importante en el manejo de la enfermedad.

Los tratamientos con B. subtilis, sulfato de cobre pentahidratado, fosfito de potasio y el testigo inoculado tuvieron una severidad media de infección de 10,04, 12,31, 15,6 y $15,75 \mathrm{~cm}^{2}$, respectivamente (Tabla 4), representando un control de la enfermedad menor a $37 \%$ para el mejor caso.

Tabla 4. Resultados del análisis de área de las infecciones por $L$. theobromae en el patrón de plantas de vid tratadas con distintos tratamientos para el control de la enfermedad

\begin{tabular}{|c|c|c|c|}
\hline Tratamientos & $\begin{array}{l}\text { Media del } \\
\text { área de } \\
\text { infección } \\
\text { real }\end{array}$ & $\begin{array}{c}\text { Media } \\
\text { transformada } \\
\text { de área de } \\
\text { infección }\end{array}$ & Agrupamiento \\
\hline Testigo inoculado & $15,75^{\mathrm{x}}$ & $4,96^{\mathrm{y}}$ & $\mathrm{A}^{\mathrm{z}}$ \\
\hline Fosfito de potasio & 15,60 & 4,93 & A \\
\hline $\begin{array}{l}\text { Sulfato de cobre } \\
\text { pentahidratado }\end{array}$ & 12,31 & 4,50 & $\mathrm{~B}$ \\
\hline Bacillus subtilis & 10,04 & 4,15 & $\mathrm{C}$ \\
\hline Ácido fosforoso & 8,25 & 3,86 & $\mathrm{D}$ \\
\hline Trichoderma harzianun & 6,28 & 3,49 & $\mathrm{E}$ \\
\hline Fosetil aluminio & 3,37 & 2,81 & $\mathrm{~F}$ \\
\hline Acibenzolar-S-metil & 0,42 & 1,48 & G \\
\hline Mananos oligosacáridos & 0,26 & 1,29 & G \\
\hline Testigo sin inocular & 0,00 & 1,00 & $\mathrm{H}$ \\
\hline $\begin{array}{l}\text { Coeficiente de } \\
\text { variabilidad }\end{array}$ & \multicolumn{2}{|c|}{$3,5 \%$} & \\
\hline
\end{tabular}

\section{Conclusiones}

Los productos de origen químico: acibenzolar-S-metil y mananos oligosacáridos son los mejores mostrando una menor incidencia, severidad y porcentajes de inhibición, mostrando su eficacia en el control de $L$. theobromae en plantas de vid. Por otra parte, los productos de origen biológicos no son eficaces en el control de la enfermedad.

\section{Literatura citada}

Abdollahzadeh, J.; Mohammadi-Goltapeh, E.; Zare, R. and Phillips, A. 2010. Phylogeny and morphology of four new species of Lasiodiplodia from Iran. Persoonia, 25:1-10.

Añon, D.; Levitan, A. y Tarino, E. 2004. Evaluación de diferentes dosis de fertilización en la producción de plantines de Pinus taeda creciendo en sustrato colonizado por Trichoderma harzianum. Tesis Ing. Agr. Montevideo, Uruguay. 125 p.

Al-Saadoon, A.; Ameen, M.; Hameed, M. and Al-Badran, 
A. 2012. Histopathology of grapevine inoculated with Lasiodiplodia theobromae. Basrah J. Agric. Sci., 25(1): $1-12$.

Barnett, H. and Hunter, B. 1996. Illustrated general of imperfect fungi. The American Phytopathological Society. U.S.A. 218 p.

Commonwealth Mycological Institute (Great Britain) \& C.A.B. International. 1974. C.M.I. descriptions of pathogenic fungi and bacteria. Kew, Surrey, England: Commonwealth Mycological Institute. 519 p.

Crous, P. and Palm, M. 1999. Reassessment of the anamorph genera Botryodiplodia, Dothiorella and Fusicoccum. Sydowia, 52:167-175.

Guest, D. 1986. Evidence from light microscopy of living tissue that fosetyl-al modifies the defense response in tobacco seedlings following inoculations by Phytophthora nicotianae var. nicotianae. Physiological and Molecular Plant Pathology, 29: 251-261.

Heath, M. 2000. Hypersensitive response-related death. Plant Molecular Biology, 44: 321-334.

Kedma, M.; Pinto, S. \& Cordeiro do Nascimiento L. 2012. Efficiency of resistance elicitors in the management of grapevine downy mildew Plasmopara viticola: epidemiological, biochemical and economic aspect. Brazil. Eur J Plant Pathol, 134: 745-754.

Kuc, J. \& Richmond, S. 1977. Aspect of the protection of cucumber against Colletotrichum lagenarium by Colletotrichum lagenarium. Phytopathology, 67: 53336.

Mandal, B.; Mandal, S.; Csinos, A. S.; Martinez, N.; Culbreath, A. K. and Pappu, H. R. 2008. Biological and molecular analyses of the acibenzolarS-methyl-induced systemic acquired resistance in flue-cured tobacco against Tomato spotted wilt virus. Phytopathology, 98: 196-204.

Matos, L.; Vivela, M.; Mathioni, S.; Araujo, M.; Ribeiro, P.; Rabelo, F.; Tadeu, A. and Vivela, L. 2013. Protective effect and expression of defense-related ESTs induced by acibenzolar-S-methyl and a phosphorylated mannan oligosaccharide-based product against Moniliophthora perniciosa in Theobroma cacao. African Journal of Biotechnology, 12(12): 13.

Ministerio de Agricultura y Riego. 2017. Estadística de producción agrícola. Disponible en: http://frenteweb. minagri.gob.pe/sisca/?mod=salida.

Mugnai, L.; Graniti, A. and Surico, G. 1999. Esca (black measles) and Brown Word-streaking: two old and elusive disease of grapevines. Plant Diseases, 83(5): 404-416.

Pearson, R. 2011. Plagas y enfermedades de la vid. Ediciones Mundi prensa. Madrid. 11 p.

Poscoe, I. and Cottral, E. 2000. Development in grapevine trunk diseases research in Australia. Phytopathologia Mediterránea, 39: 68-75.

Renault, A.; Deloire, A. and Bierne, J. 1996. Pathogenesis- related proteins in grapevines induced by salicylic acid and Botrytis cinerea. Francia Vitis, 35(1): 49-52.

Reynier, A. 1989. Manual de Viticultura. Sexta Edición. Editorial Mundi-Prensa. Madrid, España. 382p.

Rodriguez-Gálvez, Maldonado, E.. and Alves, E., 2015. Identification and pathogenicity of Lasiodiplodia theobromae causing dieback of table grapes in Perú. Eur. J. Plant Pathol. 141: 447-489

Santiago, S.; Gabriel, D.; Moctezuma V.; Ernestina \& Cibrián, D. 2015. Identificación molecular del complejo Botryosphaeria sp. asociado a cancros y secamiento de yemas en Eucalyptus sp. Revista mexicana de ciencias forestales, 6(32): 93-106.

SAS Institute. 2004. SAS/STAT. User's Guide. Version 9. Vol. 1-5.SAS Publishing. Cary. N.C. USA.

Shulaev, V.; León, J. and Raskin, L. 1995. American Society of Plant Physiologists. Salicylic Resistance Acid a Translocated Signal of Systemic Acquired in Tobacco? The Plant Cell, 7: 1691-1701.

Sutton, B. 1980. The Coelomycetes. Commonwealth Mycological Institute, kew, Surrey, England 696 p.

Urbez-Torres, J. R.; Leavitt G. M.; Guerrero, J. C.; Guevara, J. and Gubler, W. D. 2008. Identification and pathogenicity of Lasiodiplodia theobromae and Diplodia seriata, the agents causal of bot canker disease of grapevines in Mexico. Plant diseases, 92: 519-529.

Van Loon, L. \& Pieterse, C. 2006. Significance of inducible defense-related proteins in infected plants. Annu. Rev. Phytopathol, 44: 135-162.

Wang, F.; Zhao, L.; Li, G.; Huang, J. and Hsiang, T. 2011. Identification and characterization of Botryosphaeria spp. causing gummosis of peach trees in Hubei Province, Central China. Plant Disease, 95:1378-1384

Zipfel, C. 2014. Trends in immunology. Plant patternrecognition receptors. Review. 35: 345-551. 